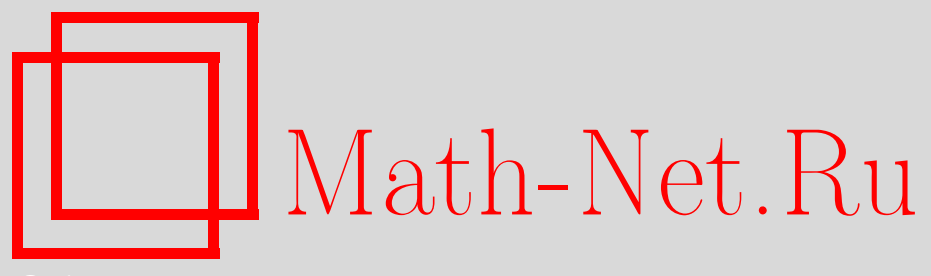

А. М. Вершик, Е. Д. Глускин, В. А. Козлов, А. А. Лаптев, Б. М. Макаров, Б. С. Митягин, П. Неваи, Г. В. Розенблюм, Т. А. Суслина, Н. Н. Уральцева, Д. Р. Яфаев, Михаил Захарович Соломяк (некролог), УМН, 2017, том 72 , выпуск 5, 181-186

DOI: https://doi.org/10.4213/rm9800

Использование Общероссийского математического портала Math-Net.Ru подразумевает, что вы прочитали и согласны с пользовательским соглашением http://www . mathnet.ru/rus/agreement

Параметры загрузки:

IP : 54.198 .187 .58

26 апреля 2023 г., 15:17:14

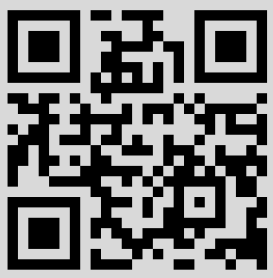




\section{Михаил Захарович Соломяк}

31 июля 2016 г. ушел из жизни Михаил Захарович Соломяк, выдающийся математик, специалист в области функционального анализа и спектральной теории, один из создателей Ленинградской (Санкт-Петербургской) школы спектральной теории операторов.

Михаил Захарович родился 16 мая 1931 г. в Ленинграде. Его отец был крупным инженером-строителем, мать преподавала русский язык и литературу. Во время войны первые блокадные месяцы семья оставалась в Ленинграде. Осенью 1941 г. отец руководил строительством укреплений на участке Ленинградского фронта. 30 января 1942 г. Михаил Захарович с матерью эвакуировались по льду Ладожского озера. Отец выехал в феврале 1942 г.; он руководил эвакуацией строительного отдела Ждановского завода

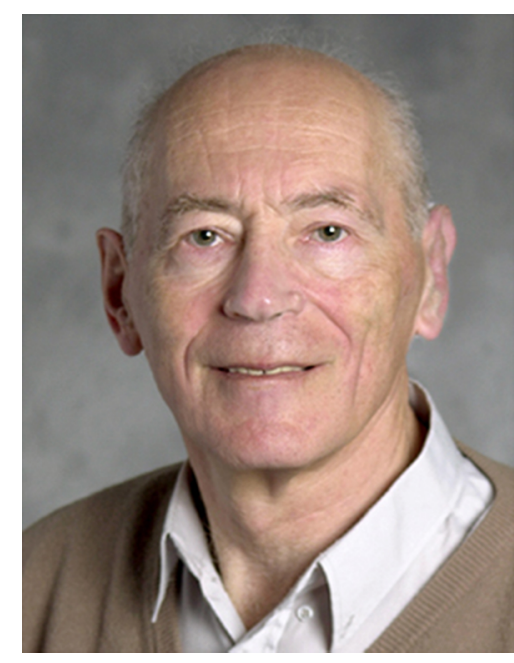
в город Зеленодольск Татарской АССР. Там отец возглавил строительство кораблестроительного завода. В 1945 г. семья вернулась в Ленинград.

C восьмого класса Михаил Захарович был участником математического кружка, организованного Виктором Абрамовичем Залгаллером. Традиции этого кружка стали основой известной системы подготовки молодых талантов. В старших классах Михаил Захарович был победителем городской олимпиады по математике. Впоследствии он сам организовывал эти олимпиады и руководил кружком для школьников.

Михаил Захарович учился на математико-механическом факультете Ленинградского государственного университета с 1948 по 1953 г. Его будущая жена Тамара училась на том же курсе. В университете Михаил Захарович увлекся функциональным анализом, предметом тогда очень новым. Его учителями были Марк Константинович Гавурин и Леонид Витальевич Канторович. После окончания университета в течение десяти лет Михаил Захарович преподавал в различных ленинградских вузах (Сельскохозяйственный институт, Кораблестроительный институт, Педагогический институт им. А. И. Герцена). В 1964 г. при поддержке Владимира Ивановича Смирнова и Ольги Александровны Ладыженской Михаил Захарович перешел в Ленинградский государственный университет, где работал вплоть до 1991 г., сначала на кафедре математической физики (руководимой В. И. Смирновым), а затем, с 1974 г., на кафедре математического анализа. В 1959 г. он защитил кандидатскую диссертацию, в 1968 г. - докторскую. В 1972 г. Михаил Захарович был направлен в Сыктывкар, где модернизировал курсы аналитического направления в университете, а после возвращения в 1974 г. он смог получить должность профессора.

DOI: https://doi.org/10.4213/rm9800 
В 1991 г. Михаил Захарович Соломяк был приглашен в ведущий научный центр Израиля - Институт Вейцмана в Реховоте, где и проработал до конца жизни.

В научной деятельности М. З. Соломяка (а им опубликовано более 140 научных работ, включая две книги) абстрактные методы функционального анализа сочетаются с конкретными рассмотрениями теории дифференциальных уравнений и вещественного анализа. Такая комбинация характерна для Ленинградской (Санкт-Петербургской) математической школы.

Ранние работы М. З. Соломяка посвящены дифференциальным уравнениям в банаховом пространстве. Для замкнутого оператора $A$, порождающего аналитическую полугруппу, были получены оценки дробных степеней. С помощью этих оценок были найдены условия на возмущение $B(t)$, обеспечивающие существование и единственность классического решения задачи Коши для уравнения

$$
u^{\prime}+A u+B(t) u=f
$$

и возможность отыскания такого решения методом последовательных приближений. Эти результаты нашли приложение к анализу параболических уравнений в пространстве $L_{p}$, что стало возможным благодаря доказанным М. З. Соломяком оценкам в $L_{p}$ резольвенты и дробных степеней эллиптического оператора произвольного порядка с граничными условиями Дирихле. Идеи, связанные с теорией возмущений, стали характерными для всего последующего математического творчества М. З. Соломяка.

Одновременно с Ж.-Л. Лионсом и Э. Мадженесом М. З. Соломяк дал явное описание пространств, сопряженных пространствам Соболева в области. Дальнейшие работы М. 3. Соломяка были посвящены общей теории эллиптических систем. Им дана гомотопическая классификация эллиптических систем на двумерных многообразиях. Показано, что при фиксированной векторной размерности эллиптическая система первого порядка может существовать лишь в пространстве не слишком большой размерности. Построен пример эллиптической системы первого порядка в четырехмерном пространстве, не допускающей корректных интегро-дифференциальных краевых задач ни в какой ограниченной области. Отметим, что эти работы предшествовали исследованиям М. Атьи и Л. Буте-де-Монвеля о топологии общих эллиптических краевых задач. Михаил Захарович нашел также чисто алгебраическую форму условия фредгольмовости краевой задачи, равносильную условию Лопатинского (которое трудно для проверки).

С середины 1960-х годов началось тесное сотрудничество Михаила Захаровича Соломяка с Михаилом Шлемовичем Бирманом, продолжавшееся более 40 лет. Они опубликовали более 60 совместных работ, включая превосходный учебник высокого уровня [5] "Спектральная теория самосопряженных операторов в гильбертовом пространстве" (выпущенный первым изданием в 1980 г., переведенный в 1987 г. издательством Рейдель и опубликованный вновь по-русски в существенно расширенной форме в 2010 г.).

Первый большой и важный цикл их совместных работ (1965-1973) посвящен изучению и развитию аппарата двойных операторных интегралов Стилтьеса (ДОИ). ДОИ впервые появились в 1951 г. у Ю.Л. Далецкого и С. Г. Крейна в связи с теорией возмущений. Потребность в этом аппарате возникла в математической теории рассеяния. В работах М.Ш. Бирмана и М. З. Соломяка были обнаружены широкие связи ДОИ с другими областями математической физики. В частности, с помощью ДОИ были получены новые (точные) достаточные условия ограниченности многомерных сингулярных интегральных операторов и псевдодифференциальных операторов, а также трансформаторов в различных классах компактных операторов.

Позднее, в 1975 г., М.Ш. Бирман и М. З. Соломяк успешно применили аналитический аппарат ДОИ к "вещественному" доказательству формулы следа для пары 
самосопряженных операторов. Их подход позволил по-новому взглянуть на теорию функции спектрального сдвига М. Г. Крейна и существенно расширил класс допустимых функций в формуле следа.

Изучая ДОИ, авторы столкнулись с рядом конкретных аналитических вопросов; разработанные при этом методы развились впоследствии в самостоятельные направления исследования. Наиболее продуктивным здесь оказалось создание нового метода кусочно полиномиальных приближений функций из классов Соболева. Особенностью этого метода явились комбинаторно-геометрические соображения, позволяющие тонко настраивать алгоритм приближения на конкретные функции и веса, что дало возможность во многих случаях получать точные по порядку и константам оценки приближения в $L_{\infty}$ и в весовых пространствах $L_{p}$. С помощью этого алгоритма были найдены точные по порядку оценки геометрических характеристик вложений пространств Соболева, а именно оценки $\varepsilon$-энтропии и поперечников. Доступное изложение метода кусочно полиномиальных приближений с детальным объяснением математических механизмов и приложений составило цикл лекций М.Ш. Бирмана и М. З. Соломяка "Количественный анализ в теоремах вложения Соболева и приложения к спектральной теории", прочитанных во время Десятой летней математической школы. Эти лекции были выпущены по-русски в трудах Школы [1] и изданы на английском языке отдельной книгой издательством Американского математического общества.

В процессе работы над ДОИ М.З. Соломяк обратился к теории интерполяции линейных операторов. Чрезвычайно продуктивной оказалась парадоксальная идея рассматривать в качестве самостоятельного объекта отображение из пространства ядер в пространство интегральных операторов, ставящее оператор в соответствие его ядру. Михаил Захарович установил интерполяционные теоремы для таких отображений, а также для их билинейных версий. На этом пути были получены важные оценки сингулярных чисел интегральных и псевдодифференциальных операторов.

С начала 1970-х годов основные научные интересы М. З. Соломяка были направлены на классическую проблему нахождения асимптотики собственных (или сингулярных) значений дифференциальных и интегральных операторов. В этой области вклад М.Ш. Бирмана и М. З. Соломяка трудно переоценить. Для чрезвычайно широких классов эллиптических дифференциальных краевых задач, во многих случаях (например, для задачи Дирихле) без каких-либо ограничений на гладкость границы области или гладкость коэффициентов, был оправдан вейлевский главный член спектральной асимптотики. Авторы совместили классический вариационный подход к исследованию собственных значений с современными методами теории возмущений. Решающими здесь оказались полученные с помощью кусочно полиномиальных приближений точные по порядку оценки собственных значений (включая усиления, найденные Г. В. Розенблюмом, учеником М. З. Соломяка). Например, вейлевская асимптотика для спектральной задачи

$$
-\Delta u=\lambda p(x) u
$$

в области $\Omega \subset \mathbb{R}^{d}, d \geqslant 3$, с граничным условием Дирихле была оправдана при единственном условии, что вейлевский коэффициент конечен. Найденный подход оказался эффективным и для других типов спектральных задач. Еще в 1970 г. М.Ш. Бирман и М. З. Соломяк установили асимптотический закон для спектра широкого класса интегральных операторов со слабой особенностью ядра на диагонали, а позднее, развив технику теории возмущений, оправдали асимптотику вейлевского типа для псевдодифференциальных операторов отрицательного порядка с анизотропно однородными символами, причем без каких-либо условий типа эллиптичности. Последний результат получил многочисленные применения в различных спектральных задачах. 
В серии работ М. Ш. Бирмана и М. З. Соломяка 1978-1982 гг. изучались спектральные свойства дифференциальных операторов и вариационных задач на подпространстве решений дифференциального уравнения или системы; примерами могут служить системы Максвелла и Стокса.

Оператор Максвелла в негладких областях и с негладкими коэффициентами особо привлекал внимание М.Ш. Бирмана и М. З. Соломяка. Основная трудность при его изучении заключается в том, что оператор неполуограничен и поэтому нельзя использовать подход через квадратичные формы. В связи с этим свойства решений не допускают описания в терминах стандартных пространств Соболева. Другая трудность - необходимость учета условий соленоидальности. В работах М.Ш. Бирмана и М. З. Соломяка (см. обзор [6]) было дано описание особенностей электрической компоненты электромагнитного поля в областях с липшицевой границей. На базе этого результата им удалось оправдать вейлевскую асимптотику частот электромагнитных колебаний для ограниченного резонатора с липшицевой границей.

Значителен вклад М. З. Соломяка в анализ спектральных задач, в которых асимптотика спектра не является вейлевской. Невейлевские формулы спектральной асимптотики были им впервые найдены для широких классов эллиптических задач с граничным вырождением, а также для оператора Шрёдингера с однородным вырождающимся потенциалом.

М. 3. Соломяк опубликовал совместно с М. Ш. Бирманом ряд обзорных статей, где излагаются и обобщаются их методы и результаты (см. [2]-[4], [6], [8]-[12]). Важную роль сыграла написанная вместе с Г. В. Розенблюмом и М. А. Шубиным обзорная статья [7] (фактически заполнившая целый том в серии "Современные проблемы математики. Фундаментальные направления"), в которой были представлены важнейшие (на то время) подходы и результаты по анализу дискретного спектра эллиптических операторов.

После переезда в Израиль М. З. Соломяк продолжил активную научную деятельность. Он исследовал вопрос о том, какие математические структуры (из многих имеющихся) на самом деле ответственны за оценку отрицательного спектра операторов вида $A(\alpha)=-\Delta-\alpha p(x)$. В совместной статье с Д. Левиным было установлено, что вместо области в $\mathbb{R}^{d}$ может выступать произвольное локально компактное пространство с борелевской мерой, а оператор Лапласа может быть заменен произвольным положительным оператором $A$, порождающим марковскую полугруппу, при единственном условии, что для квадратичной формы оператора выполнено неравенство типа Соболева. Далее, в совместной работе с Г. В. Розенблюмом была найдена иная форма абстрактных условий. Именно, предполагалось, что оператор $A$ порождает полугруппу, сохраняющую положительность и действующую ограниченно из $L_{1}$ в $L_{\infty}$. В этих условиях были найдены оценки спектра оператора $A(\alpha)$, при этом не обязательно степенного вида. Эти абстрактные результаты получили конкретные применения ко многим спектральным задачам, для которых ранее поведение спектра известно не было (например, к магнитным, релятивистским, дискретным и другим операторам).

В израильский период М. З. Соломяком были получены важные результаты в анализе спектра дифференциальных задач, в которых размерность пространства равна порядку оператора (например, взвешенный лапласиан в размерности два). Такие задачи в течение многих лет оставались вызовом исследователям: точные результаты были недоступны по причине отсутствия вложения соответствующего пространства Соболева в $L_{\infty}$. Михаил Захарович сумел использовать более слабое вложение в экспоненциальное пространство Орлича и выразить в терминах пространств Орлича оценки спектра, которые оказались точными как по порядку, так и по классам весовой функции. 
Михаил Захарович обращался в этот период и к интересным спектральным задачам, поставленным коллегами-физиками. Вместе с учениками и сотрудниками он разработал спектральную теорию операторов Лапласа и Шрёдингера на бесконечных метрических графах, в частности на деревьях, получив условия дискретности спектра и асимптотику собственных значений. Изучались также спектральные свойства операторов Лапласа и Шрёдингера в узких каналах-волноводах и параметрический переход от дискретного спектра к непрерывному в так называемой модели У. Смилянского необратимого квантового графа. Свою последнюю статью Михаил Захарович опубликовал в возрасте 82 лет.

Михаил Захарович был замечательным лектором. Его курс функционального анализа в Ленинградском университете не только обладал прекрасной внутренней логикой, но и был отлично согласован с параллельно читавшимся курсом уравнений математической физики. Вместе с М.Ш. Бирманом М. З. Соломяк создал в Ленинграде мощную научную школу по спектральной теории операторов, которая известна во всем мире. Среди учеников Михаила Захаровича более 15 кандидатов наук. Школа Бирмана-Соломяка и сейчас продолжает оказывать большое влияние на развитие спектральной теории. Многие ученики Михаила Захаровича сами стали известными математиками и заняли профессорские позиции в университетах России, Швеции, Великобритании, Болгарии и Киргизстана. В их числе И. Л. Вулис, Д. Левин, Е. Д. Глускин, В.А. Козлов, Г.Е. Караджов, А.И. Кароль, С. Кыдыралиев, А. А. Лаптев, К. Наймарк, В. А. Олевский, Г. В. Розенблюм, Г. М. Тащиян и безвременно ушедшие из жизни О. Г. Парфенов и Ю. Г. Сафаров.

Михаил Захарович сыграл важную роль в организации математической жизни в Ленинграде. Он сотрудничал с В. И. Смирновым и О. А. Ладыженской в ведении общегородского семинара по математической физике, привлекавшего математиков со всей страны. Был долгие годы членом правления Ленинградского математического общества. Создал и вел семинар по спектральной теории, где обсуждались важнейшие идеи и актуальные методы предмета.

У Михаила Захаровича была счастливая дружная семья: жена Тамара Борисовна и сын Борис - тоже математики, трое любимых внуков. Его коллеги, друзья и ученики всегда ценили его неизменную доброжелательность, простоту общения и готовность помочь.

Память о Михаиле Захаровиче Соломяке навсегда сохранится в сердцах тех, кому посчастливилось знать этого замечательного ученого и человека.

А.М. Вериик, Е.Д. Глускин, В.А. Козлов, А.А. Лаптев, Б. М. Макаров, Б. С. Митягин, П. Неваи, Г. В. Розенблюм, Т. А. Суслина, Н.Н. Уралъцева, Д.Р. Яфаев

\section{Книги и обзорные статьи М. З. Соломяка}

[1] "Количественный анализ в теоремах вложения Соболева и приложения к спектральной теории”, Десятая летняя математическая школа (Кацивели/Нальчик, 1972), Ин-т матем. АН УССР, Киев, 1974, 5-189 (совм. с М.Ш. Бирманом); англ. пер.: Quantitative analysis in Sobolev imbedding theorems and applications to spectral theory, Amer. Math. Soc. Transl. Ser. 2, 114, Amer. Math. Soc., Providence, RI, 1980, viii+132 pp. (with M. Sh. Birman).

[2] "Оценки сингулярных чисел интегральных операторов", УМH, 32:1(193) (1977), 17-84 (совм. с М.Ш. Бирманом); англ. пер.: "Estimates of singular numbers of integral operators", Russian Math. Surveys, 32:1 (1977), 15-89 (with M. Sh. Birman). 
[3] "Асимптотика спектра дифференциальных уравнений”, Итоги науки и техн. Сер. Матем. анал., 14, ВИНИТИ, М., 1977, 5-58 (совм. с М.Ш. Бирманом); англ. пер.: "Asymptotic behavior of the spectrum of differential equations", J. Soviet Math., 12:3 (1979), 247-283 (with M. Sh. Birman).

[4] "Применение интерполяционных методов к оценкам спектра интегральных операторов", Теория операторов в функииональных пространствах, Наука, Новосибирск, 1977, 42-70 (совм. с М.Ш. Бирманом).

[5] Спектральная теория самосопряженных операторов в гильбертовом пространстве, Изд-во Ленингр. ун-та, Л., 1980, 264 с. (совм. с М.Ш. Бирманом); 2-е изд., испр. и доп., Лань, СПб., 2010, 464 с.; англ. пер.: Spectral theory of self-adjoint operators in Hilbert space, Math. Appl. (Soviet Ser.), 5, D. Reidel Publ. Co., Dordrecht, 1987, xv+301 pp. (with M. Sh. Birman).

[6] " $L_{2}$-теория оператора Максвелла в произвольных областях", УМH, 42:6(258) (1987), 61-76 (совм. с М.Ш. Бирманом); англ. пер.: " $L_{2}$-theory of the Maxwell operator in arbitrary domains", Russian Math. Surveys, 42:6 (1987), 75-96 (with M. Sh. Birman).

[7] "Спектральная теория дифференциальных операторов", Дифференциальные уравнения с частными производными - 7, Итоги науки и техн. Сер. Соврем. пробл. матем. Фундам. направления, 64, ВИНИТИ, М., 1989, 5-242 (совм. с Г. В. Розенблюмом, М. А. Шубиным); англ. пер.: "Spectral theory of differential operators", Partial differential equations VII, Encyclopaedia Math. Sci., 64, Springer, Berlin, 1994, 1-261 (with G. V. Rozenblyum, M. A. Shubin).

[8] "Операторное интегрирование, возмущения и коммутаторы", Исследования по линейным операторам и теории функиий. 17, Зап. науч. сем. ЛОМИ, 170, Изд-во "Наука", Ленингр. отд., Л., 1989, 34-66 (совм. с М.Ш. Бирманом); англ. пер.: "Operator integration, perturbations, and commutators", J. Soviet Math., 63:2 (1993), 129-148 (with M. Sh. Birman).

[9] "Estimates for the number of negative eigenvalues of the Schrödinger operator and its generalizations", Estimates and asymptotics for discrete spectra of integral and differential equations (Leningrad, 1989-1990), Adv. Soviet Math., 7, Amer. Math. Soc., Providence, RI, 1991, 1-55 (with M. Sh. Birman).

[10] "Schrödinger operator. Estimates for number of bound states as function-theoretical problem", Spectral theory of operators (Novgorod, 1989), Amer. Math. Soc. Transl. Ser. 2, 150, Amer. Math. Soc., Providence, RI, 1992, 1-54 (with M. Sh. Birman).

[11] "On the eigenvalue behaviour for a class of differential operators on semiaxis", Math. Nachr., 195 (1998), 17-46 (with M. Sh. Birman, A. Laptev).

[12] "Double operator integrals in a Hilbert space", Integral equations operator theory, 47:2 (2003), 131-168 (with M. Sh. Birman). 